\title{
High-latitude ionospheric convection models derived from Defense Meteorological Satellite Program ion drift observations and parameterized by the interplanetary magnetic field strength and direction
}

\author{
Vladimir O. Papitashvili \\ Space Physics Research Laboratory, University of Michigan, Ann Arbor, Michigan, USA
}

Frederick J. Rich

Air Force Research Laboratory, Space Vehicles Directorate, Hanscom Air Force Base, Massachusetts, USA

Received 14 August 2001; revised 18 December 2001; accepted 19 December 2001; published 22 August 2002.

[1] A series of new high-latitude ionospheric convection models have been constructed using Defense Meteorological Satellite Program (DMSP) thermal ion drift measurements. The models are obtained by sorting cross polar cap electrostatic potentials into magnetic latitude/magnetic local time bins. A regression analysis of the potentials in each bin is then implemented for establishing the relationships to the interplanetary magnetic field (IMF) for three seasons: summer, winter, and equinox. A linear modeling formula for the ionospheric electrodynamics (LIMIE) yields a convection response to the average solar wind (i.e., the "quasi-viscous" interaction) and to changes in the IMF $B_{y}, B_{z} \leq 0$, and $B_{z}>0$ components. The modeled convection is a superposition of the first two parameters with either the IMF $B_{z} \leq 0$ or the $B_{z}>0$ component. A global model is created by fitting the regression analysis results to a spherical harmonic function. The resulting DMSP-based ionospheric convection model (DICM) is fully parameterized by the IMF strength and direction. With this model, ionospheric convection patterns can be generated for any IMF configuration during quiet to moderate geomagnetic conditions. We compare the DICM model with other available high-latitude convection patterns organized by the IMF. The new elements in DICM are its quasi-viscous and separate IMF-dependent terms for both the northern and southern polar regions, which are not explicitly found in other ionospheric convection studies. The DICM's seasonal dependence and interhemispheric symmetry/asymmetry features show that the summer cross-polar potentials are $10-15 \%$ smaller than the winter potentials. The latter is in agreement with the seasonal dependence of field-aligned currents and with the voltage-current relationship required for the proper magnetosphereionosphere coupling. INDEX TERMS: 2411 Ionosphere: Electric fields (2712); 2712 Magnetospheric Physics: Electric fields (2411); 2708 Magnetospheric Physics: Current systems (2409); 2409 Ionosphere: Current systems (2708); 2463 Ionosphere: Plasma convection; KEYWORDS: polar cap, ionospheric electrodynamics, plasma convection, current systems

\section{Introduction}

[2] Earth's magnetosphere is immersed in the solar wind (SW) plasma that carries the "frozen-in" interplanetary magnetic field (IMF). This results in continuous interactions through "quasi-viscous" and merging processes. The interplanetary electric field $\mathbf{E}_{\mathrm{SW}}=-\mathbf{V}_{\mathrm{SW}} \times \mathbf{B}_{\mathrm{IMF}}$ partially penetrated the magnetopause couples to an electric field across the high-latitude ionosphere. The resulting convective flow of ionospheric plasma mainly follows a two-cell pattern with the antisunward flow over the geomagnetic pole; this pattern can be significantly distorted by deviation

Copyright 2002 by the American Geophysical Union. 0148-0227/02/2001JA000264 of the IMF "clock-angle" vector $\mathbf{B}_{T}=\left[B_{y}, B_{z}\right]$ from the purely southward direction [e.g., Wolf, 1970; Feldstein and Levitin, 1986; Heppner and Maynard, 1987]. However, neither theoretical models of the solar wind-magnetosphere interaction or experimental observations predicts or shows evidence of ionospheric convection generated by merging with IMF $B_{x}$ component [e.g., Crooker, 1992; Crooker and Rich, 1993]. Therefore throughout this paper we follow the common assumption that the IMF $B_{x}$ component is ineffective in the large-scale solar wind-magnetosphere interaction.

[3] High-latitude ionospheric convection maps have been produced in many studies [e.g., Hairston and Heelis, 1990; Rich and Hairston, 1994; Weimer, 1995; Ruohoniemi and Greenwald, 1996] (to name just a few). 
Although organized according to the IMF clock angle, these patterns lack full parameterization by the IMF strength and direction. Weimer [1996, 2001a] obtained a partial parameterization with his DE 2 satellite-based electrostatic potential field model by simply interpolating spherical harmonic coefficients obtained for 16 different IMF clock angles and three magnitude ranges. The Institute of Terrestrial Magnetism, Ionosphere, and Radio Wave Propagation (Russian Academy of Sciences) electrodynamic model (IZMEM), which is based on ground-based magnetometer data, is the only model fully parameterized by the IMF/SW strength and direction [Levitin et al., 1982; Feldstein and Levitin, 1986; Papitashvili et al., 1990, 1994]. The IZMEM model was created using a regression analysis (i.e., correlations between the IMF and ground magnetometer data) and the "magnetograms inversion technique" (MIT) in a framework of the linear modeling of ionospheric electrodynamics (LIMIE). The model described in this paper applies a similar technique to the data from spacecraft of the Defense Meteorological Satellite Program (DMSP).

[4] Recently, Papitashvili et al. [1999] applied the LIMIE approach to electrostatic potentials inferred from the crosstrack ion drift velocities measured on board the DMSP satellites F8 and F10-F13 in 1993-1996. The DMSP data were collected into 4-month (2-month) intervals centered at the solar solstices (equinoxes) and analyzed separately over the northern and southern polar regions. The result is the IZMEM/DMSP model, which uses the convection patterns defined by the ground geomagnetic field observations, but the electric potentials are scaled by the satellite observations.

[5] For this study we extend the results obtained by Papitashvili et al. [1999] to construct new DMSP-based ionospheric convection models (DICM) as a function of IMF conditions. Following the method used to construct the IZMEM model, a regression analysis scheme is used to determine the variation of electrostatic potential at given high-latitude positions as a function of IMF $B_{y}$ and IMF $B_{z}$. Then we apply spherical harmonic expansions to each set of regression coefficients and the residual terms. Distributions of residual term values represent the background, IMF-independent pattern of ionospheric potentials. The regression coefficients represent distributions of the convection's responses over the polar region to continuous changes in the corresponding IMF component. As a result, we obtained a complete set of the DICMs for both the northern and southern polar regions and for three different geomagnetic dipole tilts (i.e., summer, winter, and equinox). Following an approach suggested by Ruohoniemi and Greenwald [1996], we compare our results with those of other ionospheric convection models.

[6] The obtained DICM's seasonal dependence shows that the summer cross-polar potentials are $10-15 \%$ smaller than the winter potentials. Although this difference appears insignificant, it may appear relevant to the voltage-current relationship of the solar wind-magnetosphere-ionosphere coupling where the region 1 field-aligned currents provide a feedback. In this study we suggest a possible mechanism where the strongly season-dependent R1 currents cause an imbalance in the cross-polar potentials delivered into the sunlit (summer) and dark (winter) polar caps from the reconnection site at the magnetopause.

\section{Data and Method}

[7] The thermal ion drifts at altitudes of $\sim 840 \mathrm{~km}$ have been measured by the DMSP satellites F8-F15 from 1987 to present. The ionospheric electric field component parallel to the satellite velocity vector is calculated as $E_{\|}=-\mathbf{V}_{\perp}$ $\times \mathbf{B}_{\text {IGRF}}$ ) at and above $\pm 50^{\circ}$ corrected geomagnetic (CGM) latitude. $\mathbf{V}_{\perp}$ represents the component of the ion flow perpendicular to the spacecraft velocity and in the horizontal plane. $\mathbf{B}_{\mathrm{IGRF}}$ represents the geomagnetic field calculated at the satellite location from the International Geomagnetic Reference Field (IGRF) model for the given epoch [Barton, 1997]. Integrating the electric field, one can obtain a measure of the electrostatic potential along the satellite orbit. This potential is first corrected by removing the corotation potential. The residual potential is adjusted to force the potential to zero at the latitude a few degrees equatorward of the auroral oval [Hairston and Heelis, 1993]. If large adjustment is required, the pass is rejected because it probably contains large temporal variations or some other effects. Rich and Hairston [1994] utilized these data in defining average electrostatic potentials at high latitudes using DMSP F8-F9 ion drift data for 1987-1990 and separated by seasons and eight IMF clock-angle orientations. However, their maps were pictorial rather than quantitative because of manual smoothing of the contours.

[8] The DMSP data acquisition and analysis techniques used in this study have been described by Papitashvili et al. [1999]. In brief, we applied a regression analysis to correlate the IMF data with the DMSP electrostatic potentials for 1993-1996. A separate analysis was performed on DMSP data collected during a given season within a bin of $1^{\circ}$ latitude $\times 0.5$ hour magnetic local time $\left(7.5^{\circ}\right.$ in longitude) over both the northern and southern polar regions above $\pm 50^{\circ} \mathrm{CGM}$ latitudes. The total bins number in the constructed grid was $1920=40 \times 48$. Using the OMNI data set [King and Papitashvili, 1994], each DMSP electrostatic potential was tagged with the mean IMF for the current UT hour if the satellite observation was taken between 30 and $60 \mathrm{~min}$ of that hour. The DMSP records taken between 0 and 30 min of a given UT hour were tagged with the mean IMF of the previous hour. The DMSP data were collected in each bin during a given season (summer, winter, or equinox) and were separated according to the IMF $B_{z} \leq 0$ and $B_{z}>0$ conditions.

[9] In this approach, ionospheric potentials $\Phi$ observed within a given bin (specified by the bin's center CGM latitude $\phi$ and magnetic local time (MLT)) is linearly related to the corresponding IMF component values [e.g., Papitashvili et al., 1981, 1994] as

$$
\Phi(\phi, \mathrm{MLT})=K_{\Phi B_{x}} B_{x}+K_{\Phi B_{y}} B_{y}+K_{\Phi B_{z}} B_{z}+\Phi_{0} .
$$

[10] Here $K_{\Phi B_{x y z}}$ are the regression coefficients between the potentials $\Phi$ (all measurements fallen in a given bin) and IMF components for the selected season; that is, these coefficients show the ionospheric potential responses to continuous changes in the corresponding IMF component. 
The residual term $\Phi_{0}$ represents the IMF-independent ionospheric convection for average solar wind conditions (e.g., $n=5 \mathrm{~cm}^{-3}, V=400 \mathrm{~km} / \mathrm{s}$ ).

[11] Equation (1) is the basic equation of the LIMIE framework; the latter consists of four basic elements, excluding the ineffective term $K_{\Phi B_{x}}$. The LIMIE basic elements are: (1) $\Phi_{0}$ is the IMF-independent, two-cell background convection caused by presumably quasi-viscous interaction of the solar wind with the magnetosphere; (2) $K_{\Phi B_{y}}$ is the lobe convection cell controlled by the IMF $B_{y}$ component; (3) $K_{\Phi B_{z}}\left(B_{z} \leq 0\right)$ is the merging two-cell convection controlled by the IMF $B_{z}$ southward component; and (4) $K_{\Phi B_{z}}\left(B_{z}>0\right)$ is the near-pole, two-cell "reverse" convection caused by the IMF northward component $B_{z}>0$. We note that only three of these elements can coexist (i.e., combine together) simultaneously; the latter two elements replace each other depending on the IMF $B_{z}$ orientation. It is possible to split the $B_{y}$ related term in equation (1) into two subelements (for $B_{y}<0$ and $B_{y}>0$ ) and to expand the residual term in equation (1) to reflect changes in the solar wind velocity (e.g., $\left.V^{2}\right)$ and pressure $\left(n V^{2}\right)$ [e.g., Papitashvili et al., 1990], but we did not do that here. The solar wind-magnetosphere interaction may be nonlinear, especially for strong interactions during storms [Siscoe et al., 2002], but is fairly linear for most conditions [e.g., Burke et al., 1999].

[12] Therefore, although we refer above our $\Phi_{0}$ term almost explicitly to quasi-viscous interaction, we would express a word of caution because this term may also be due in part to other factors (e.g., $K_{\Phi B_{z} * B_{y}}$ or similar) relevant to more complex storm-time interaction between the solar wind and Earth's magnetosphere. Thus our model should be reasonably accurate for quiet to moderately disturbed geomagnetic conditions.

[13] The DMSP satellite orbits are Sun synchronous in either the dawn-dusk or roughly morningside (0700-1000 LT) to early eveningside (1900-2200 LT) orientation. Therefore it is expected that both the northern and southern polar regions will be covered by satellite observations mainly over the dawn-dusk magnetic local times; the lesser coverage is expected for the early afternoon and postmidnight MLT sectors. In addition, upon applying the linear regression analysis to the data in each bin according to equation (1), the results were discarded from the further analysis if the correlation coefficients between the DMSP potentials and IMF data in a given bin were $<0.35$ or if the residual term values exceeded $35 \mathrm{kV}$. According to Reiff et al. [1981], $\left|\Phi_{0}\right|>35 \mathrm{kV}$ is considered as unrealistic for the background potentials.

[14] Shaded areas in Figure 1 show the final coverage of both polar regions during different seasons where useful residual terms or regression coefficients were defined after sorting of original DMSP observations according to given IMF conditions. These data were then utilized in the spherical harmonic analysis (SHA) described in section 3.1. As seen, the obtained coverage is better in general for the Southern Hemisphere and for the background convection (top row). The coverage is also favorable for the $B_{z}<0$ and $B_{y}$ related patterns (bottom and second from the top rows, respectively); the lesser coverage is obtained for the $B_{z}>0$ patterns. The number of bins with data that can be used for SHA varies from 237 (northern summer, $B_{z}>0$ ) to
1099 (southern summer, IMF $\approx 0$ ), with the average number 710 (out of all available 1920 bins in the constructed grid). Reliable spherical harmonic expansion coefficients can be obtained if the coverage of bins are spatially well-distributed data. As seen from Figure 1, most of the data distributions were favorable for the analysis, and realistic convection patterns have been produced for all four basic elements of the high-latitude ionospheric convection.

[15] In this study we utilized a classic scheme for the spherical harmonic expansions [Langel, 1991] for the function of high-altitude DMSP electrostatic potentials by making $\Phi$ real and combining the normalization coefficients with $g_{n}^{m}$ and $h_{n}^{m}$ [e.g., Weimer, 1995; Ruohoniemi and Greenwald, 1996],

$$
\begin{aligned}
\Phi(\Theta, \lambda)= & \sum_{n=0}^{N} a_{n}^{0} P_{n}^{0}(\cos \theta) \\
& +\sum_{n=1}^{N} \sum_{m=1}^{n}\left(a_{n}^{m} \cos (m \lambda)+b_{n}^{m} \sin (m \lambda)\right) P_{n}^{m}(\cos \theta) .
\end{aligned}
$$

[16] The function is expanded in the spherical coordinates $(r, \theta, \lambda)$ with a unit radius $r=R_{E}+h_{i}\left(R_{E}=6371 \mathrm{~km} ; h_{i}=\right.$ $115 \mathrm{~km}$ ), the CGM colatitude $\theta=90^{\circ}-\phi$, and the CGM longitude expressed as $\lambda=$ MLT $\times 15^{\circ}$. Here we assume the GCM latitude/MLT coordinate system is spherically orthogonal. We confine the potential field under consideration within high latitudes $\left(\phi> \pm 50^{\circ}\right)$. We follow the scheme suggested by Weimer [1996] in deciding when to make a selection of the appropriate expansion's order and degree by comparing residuals between the best fit function and all data points. Thus all available data (for a given set of regression coefficients) were fit with two-dimensional functions over a hemispherical surface, and then the contour maps were subsequently synthesized for the polar regions from the obtained SHA coefficients.

[17] For this study, SHA was carried out using the DMSP potentials as a scalar field. By trial and error the expansion limit $n$ was varied from 8 to 12 , and the limit of $m$ was varied from 2 to 3 to obtain the correct potential pattern with the fewest terms. For example, the $\Phi_{0}$ and $\Phi\left(B_{y}\right)$ patterns were obtained for $n=10$ and $m=2$. The northward IMF $\Phi$ $\left(B_{z}>0\right)$ patterns were obtained for $n=9$ and $m=2$. The southward IMF $\Phi\left(B_{z} \leq 0\right)$ patterns were obtained for $n=8$ and $m=3$.

\section{Results}

\subsection{Basic DICM Patterns}

[18] Figure 1 shows the DICM basic convection patterns obtained for both the northern and southern polar regions using the LIMIE approach and spherical harmonic expansions. Each row presents the pattern obtained from one of the four basic factors of the model. Although it seems that not all the patterns have a satisfactory data coverage, the average number of bins with usable data per dial plot is 640 in the Northern Hemisphere and 780 in the Southern Hemisphere. These numbers constitute $\sim 35 \%$ coverage of the entire grid, which is enough for the SHA expansions. Also, the lower latitude areas near noon/afternoon and 


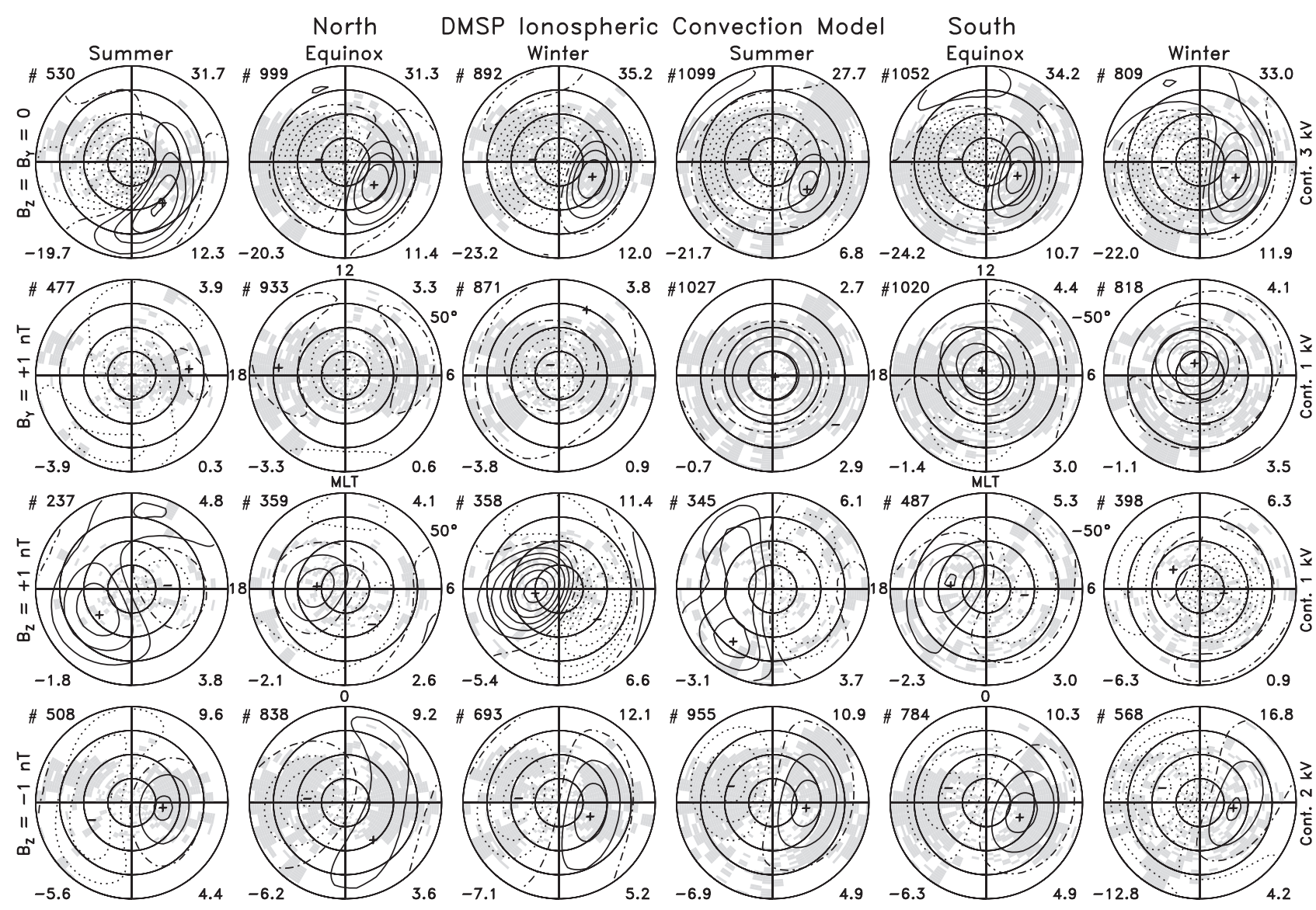

Figure 1. Contour plots of the linear modeling formula for ionospheric electrodynamics (LIMIE) basic ionospheric convection patterns obtained from the Defense Meteorological Satellite Program (DMSP) electrostatic potential data over both the northern (left) and southern (right) polar regions. The top row shows convection patterns for IMF $\approx 0$ derived for summer, equinox, and winter; the following rows (from top to bottom) show convection responses on 1-nT changes in the IMF $B_{y}, B_{z}>0$, and $B_{z}<0$ components, respectively. The numbers at lower corners of each dial show the minimum/maximum potentials, marked by dashes and crosses at the plots, respectively. The corresponding cross-polar potential drop $\Delta \Phi=\Phi_{\max }-\Phi_{\min }$ in kilovolts is shown at the upper right corner of each dial plot. The zero potential contours are plotted as a dash-dot line; the contour intervals for the positive and negative cells are printed at the right edge of each side. Shaded areas show where data usable for spherical harmonic analysis (SHA) exist after binning the data and doing the regression analysis; the number of available data bins is printed at the upper left corners of each dial plot.

midnight/postmidnight local time have little or no satellite observations, owing to the DMSP satellite orbit orientations. Nevertheless, the satellite orbit orientations are favorable for collecting data over the potential extrema locations for almost all presented patterns.

[19] As expected, the best coverage was achieved for the IMF $B_{z}<0$ and $B_{y}$ patterns, as well as for the background convection; a fewer number of data points was available for constructing IMF $B_{z}>0$ patterns. The background potentials (Figure 1) show the standard two-cell convection pattern, where the cross-polar potential drop $\Delta \Phi_{0}=\Phi_{0}^{\max }$ $-\Phi_{0}^{\min }$ varies from $28.5 \mathrm{kV}$ (southern summer) to $35.2 \mathrm{kV}$ (northern winter). The numbers are close through all six patterns (top row), averaging $\Delta \Phi_{0}=33.2 \pm 2.4 \mathrm{kV}$ and showing no recognizable seasonal effect. However, the background potential distributions are asymmetric regarding to the noon-midnight meridian in both hemispheres; the negative dusk-side cell dominates everywhere, extending far enough over the noon meridian in the near-pole area. Unfortunately, we cannot compare these background patterns with any other available models based on satellite or radar data because none of these models has an explicit background IMF-independent potential pattern. Only models based on ground magnetometer data [Friis-Christensen et al., 1985, Figure 4; Papitashvili et al., 1994, Figure 3] show these background patterns. The background patterns based on ground magnetometer data are also asymmetric with dominant dusk cells, especially for the equinox and winter patterns. Because of the good data coverage used for construction of the DICM background patterns, we believe that this asymmetry is a natural effect in the quasi-viscous interaction of the solar wind with Earth's magnetosphere. The dayside/nightside differences in the ionospheric conductivity may be a contributing cause of asymmetry.

[20] The ionospheric convection responses (measured similarly in terms of the dawn-dusk cross-polar potential) 
on a 1-nT change in the IMF $B_{z}<0$ component (Figure 1) vary from $\Delta \Phi_{B_{z-}}=9.8 \mathrm{kV} / \mathrm{nT}$ (northern equinox) to $\Delta \Phi_{B_{z-}}=$ $17.0 \mathrm{kV} / \mathrm{nT}$ (southern winter). One can see here that the summer and equinox values are close, but the cross-polar potentials "summer-to-winter" ratio is $0.81(0.69)$ in the northern (southern) polar cap; this suggests the seasonal dependence of mapping the reconnection potential from the magnetopause down to ionospheric altitudes. However, we cannot explain this "seasonal" effect by the apparent differences in the ionospheric conductance of the sunlit and dark polar caps. We notice that for the same seasons (i.e., summer-to-summer, etc.) the cross-polar potentials in the southern polar cap are 15-30\% larger than in the northern polar cap. This may suggest some imbalances in the interhemispheric potentials, possibly caused by different geometry of the field-aligned currents flowing into the northern and southern polar ionospheres. We also note that the IMF $B_{z}<0$ patterns are almost symmetric about the noon-midnight meridian.

[21] The reverse convection, dusk-dawn cross-polar potentials (Figure 1) do not show the seasonal dependence in the northward IMF 1-nT ionospheric responses; moreover, in this case the northern polar cap average response amounts to $\Delta \Phi_{B_{z+}}=-7.4 \mathrm{kV} / \mathrm{nT}$, against $\Delta \Phi_{B_{z+}}=-6.4$ $\mathrm{kV} / \mathrm{nT}$ in the Southern Hemisphere. We should admit that the data coverage for this case was not favorable for obtaining reliable patterns, and we think that our numbers overestimate the actual reverse cross-polar potentials.

[22] For the IMF $B_{y}$ component the "cross-center" potential drop is measured relative to an extreme in the center of polar cap (Figure 1). Taking into account that the average potential drops are $\Delta \Phi_{B_{y}}=-4.3 \mathrm{kV} / \mathrm{nT}$ and $\Delta \Phi_{B_{y}}=$ $-4.2 \mathrm{kV} / \mathrm{nT}$ in the northern and southern polar caps, respectively, we might conclude that the interhemispheric symmetry is good here. However, the seasonal effect is also recognizable in these patterns, where the cross-center potential drop increases by $\sim 10-20 \%$ in winter.

[23] The ionospheric convection responses obtained in this study are close to the results obtained by Papitashvili et al. [1994, 1999] and Ridley et al. [1997]. However, again it is impossible to compare our numbers with other available high-latitude ionospheric convection models because they do not separate the corresponding IMF component responses from background cross-polar potentials, showing only the combined background and the IMF clock-angle patterns plotted for the certain IMF magnitude or range. Therefore we continue our analysis with the combined IMF clock-angle patterns.

\subsection{IMF-Dependent DICM Patterns}

[24] To our knowledge, Friis-Christensen and Wilhjelm [1975] were the first to present statistical maps of the polar magnetic perturbation vectors in the form of dial plots organized according to the IMF clock angle; that is, the plot position depends on the IMF vector angle in GSM $Y-Z$ plane. Since then it has become common practice in many follow-up studies to plot ionospheric convection maps in that manner. For the IMF northward (i.e., the clock angle equals zero) the dial plot is placed at the top center of the figure; then the dials are placed clockwise incrementally by the $45^{\circ}$ increases in the clock angle. For the IMF southward the dial plot is placed at the bottom center, and for purely azimuthal IMF the dials are either placed on the right or left sides.

[25] To undertake a comparative study, we modeled the DICM patterns for the IMF $B_{T}=\left(B_{y}^{2}+B_{z}^{2}\right)^{1 / 2}=5 \mathrm{nT}$ and the average solar wind conditions $\left(n=5 \mathrm{~cm}^{-3}, V=400\right.$ $\mathrm{km} / \mathrm{s}$ ). These conditions were suggested by the Global Geospace Circulation Modeling Steering Committee [Siscoe, 1998] for test runs of various MHD-based algorithms in modeling the solar wind-magnetosphere coupling. In the following figures we show a series of the IMF-dependent DICM patterns constructed for both the northern and southern polar regions and for all seasons. We plotted these models in pairs: for the northern and southern equinoxes (Figure 2), for the northern summer and southern winter (Figure 3), and for the northern winter and southern summer (Figure 4). This organization allows interhemispheric comparisons of various high-latitude convection features (including the cross-polar potentials and pattern shapes) for better understanding the underlying physics of the magnetosphere-ionosphere coupling. However, comparing the interhemispheric summer-to-summer and winter-to-winter patterns, we can also address the symmetry/asymmetry issues in the high-altitude convection; this will help in validating the data sets obtained in different hemispheres.

[26] First, we address the symmetry/asymmetry issues for the ionospheric convection during equinox. Figure 2 shows that, in general, the potential patterns are very similar for all IMF clock angles, as well as for the IMF $\approx 0$ pattern, which is equivalent the background pattern. The cross-polar dawndusk potential drop $\Delta \Phi$ varies from $31 \mathrm{kV}$ for the northern background convection to $88 \mathrm{kV}$ for the southern $B_{z}<0$ pattern. Overall, the southern and northern patterns are very similar. Thus we conclude that during equinox the magnetosphere-ionosphere coupling supplies the magnetospheric potential almost equally to both the northern and southern polar ionospheres.

[27] The IMF $B_{y}$ effect on the high-latitude convection is clearly seen when $B_{z}=0$ (middle row of Figure 2); it adds/ subtracts additional potentials to the background pattern in each hemisphere according to the corresponding IMF azimuthal component direction. The negative dusk cell still dominates and causes significant asymmetry in the hemispheric patterns for the same sign of $B_{y}$ component; however, the $B_{y}$-controlled patterns become almost symmetrical in the northern and southern polar caps for different signs of the IMF azimuthal component. Here we can clearly see that the actual cause of the dusk-cell dominance in the convection patterns is the dusk-dawn asymmetry of the background convection rather than the pure IMF $B_{y}$ effect, as noted by Weimer [1995, 2001a] and Ruohoniemi and Greenwald [1996].

[28] The reverse dusk-dawn potential for $B_{z}=+5 \mathrm{nT}$ reduces significantly the overall background potential patterns, making the resulting distributions weak and undistinguished. However, an increase in the either $B_{y-}$ or $B_{y+}$ content results in the standard-like two-cell patterns. This suggests that the global convection is still the standard-like two-cell type, even if the reverse, sunward flow, is added to the dayside of the background pattern for $B_{z}=+5 \mathrm{nT}$. Modeling these patterns for $B_{z}=+10 \mathrm{nT}$ reveals a clear reverse flow at the dayside (not shown). 


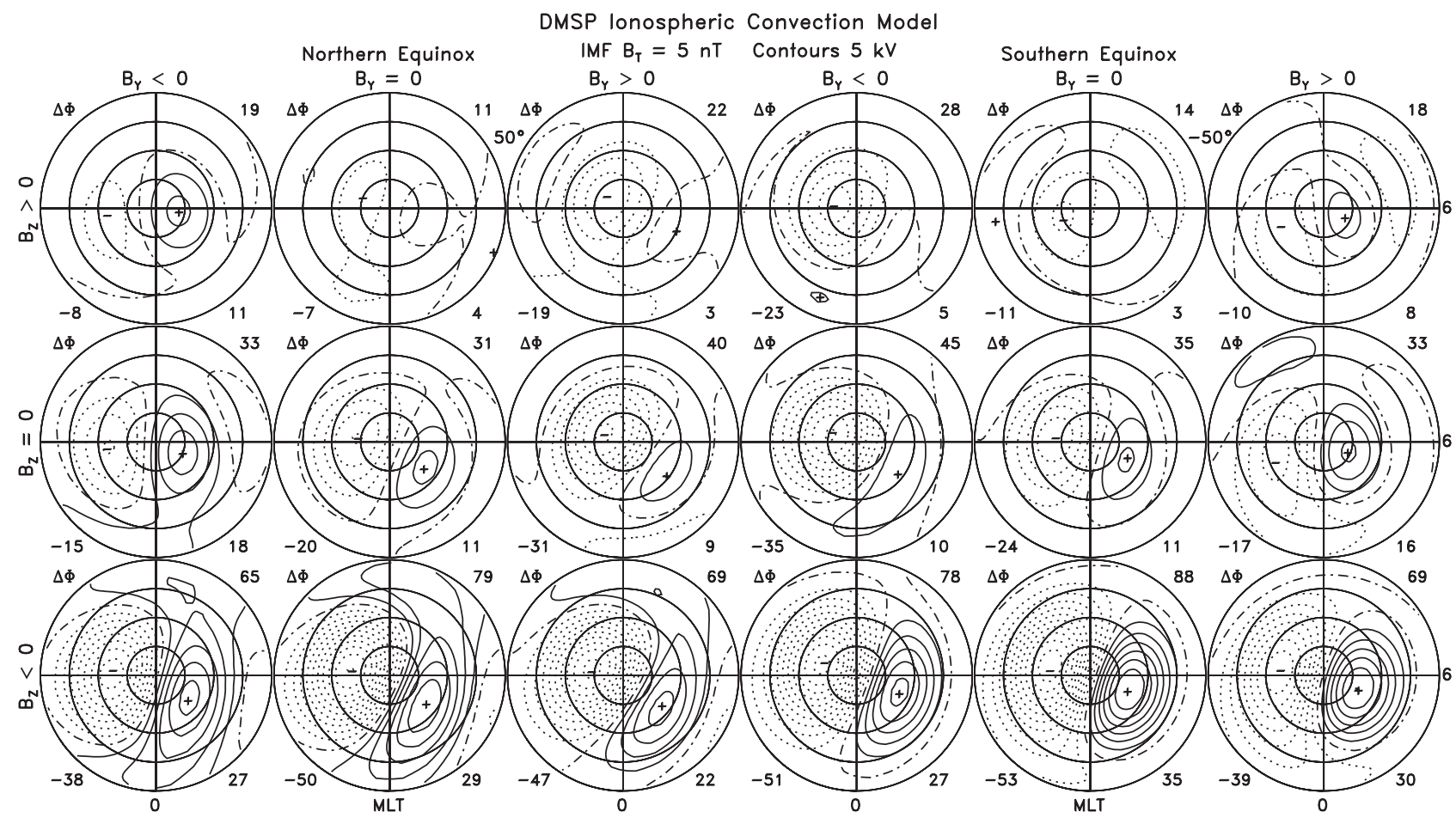

Figure 2. Contour plots of the DMSP-based IMF-dependent high-latitude ionospheric convection patterns modeled for northern (left) and southern (right) equinoxes. The dial plot in the center shows the background convection for IMF $\approx 0$; other eight dial plots are organized according to the IMF "clockangle" vector $B_{T}=\left(B_{y}^{2}+B_{z}^{2}\right)^{1 / 2}=5 \mathrm{nT}$. The numbers at lower corners of each dial show the minimum/ maximum potentials, marked by dashes and crosses at the plots, respectively. The corresponding crosspolar potential drop $\Delta \Phi=\Phi_{\max }-\Phi_{\min }$ in kilovolts is shown at the upper right corner of each dial plot. The zero potential contours are plotted as a dash-dot line; the contour intervals for the positive and negative cells are $5 \mathrm{kV}$.

[29] Figures 3 and 4 show the DICM patterns for the northern summer/southern winter and for the northern winter/southern summer, respectively; all contour plots are organized and labeled here in the same manner as in Figure 2. The background convection patterns (central dial plots) have been discussed above in the discussion of Figure 1. The background potential patterns do not show any recognizable seasonal effect, but they show certain dawn-dusk asymmetry with the dominant dusk cell. The dusk convection cell for positive (negative) IMF $B_{y}$ has 2-6 times more voltage than the dawn cell during all seasons in the Northern (Southern) Hemisphere; the convection cells are nearly equal in voltage for the opposite $B_{y}$ polarities. This effect has been shown for summer by Crooker and Rich [1993].

[30] The summer-to-summer and winter-to-winter comparisons reveal that the combined effect of the viscous and reconnection processes produces the smaller cross-polar potential drop in one hemisphere, $\Delta \Phi=74 \mathrm{kV}(94 \mathrm{kV})$ during summer (winter) in the Northern Hemisphere and $\Delta \Phi=83 \mathrm{kV}(115 \mathrm{kV})$ in the Southern Hemisphere. Similar asymmetry is seen from the summer-to-winter comparisons; the cross-polar potentials are $10-20 \%$ larger in winter. However, this asymmetry is not seen at all in the crosspolar potentials for the northward IMF, probably because the $B_{z}>0$ reverse convection weakens the overall control of the background potentials.
[31] The summer-to-winter asymmetry is mixed for the combined effect of the background and $B_{y}$-controlled patterns; it seems that the winter patterns show larger crosspolar potentials in general (up to $20 \%$ in average), but the $B_{y}<0$ patterns (for $B_{z}=0$; Figure 4 ) show a decrease in the cross-polar potential drop from summer to winter. Therefore we conclude that the summer-to-winter ratio of $\sim 0.85$ is clearly seen only in the combined background (IMF $\approx 0$ ) and reconnection $\left(B_{z}<0\right)$ patterns; the $B_{y}$-controlled lobe reconnection may show similar $\sim 20 \%$ increase in winter, but the latter results are inconclusive at this time.

\subsection{IMF-Dependent IZMEM/DMSP Patterns}

[32] Friis-Christensen et al. [1985] followed the regression analysis technique first introduced by the IZMEM group [e.g., Belov et al., 1977; Afonina et al., 1980; Mansurov et al., 1981; Levitin et al., 1982; Feldstein et al., 1984; Papitashvili et al., 1981, 1990]. Then they fed the resulting Greenland magnetometer responses onto the IMF changes and the background magnetometer patterns into the KRM magnetogram inversion technique [Kamide et al., 1981] and presented their results in an IMF clock-angle fashion. In this way, as noted by Papitashvili et al. [1994], the cited study is the only one that followed the IZMEM approach closely.

[33] However, Papitashvili et al. [1994] presented only the contour plots of the IZMEM basic elements (similar to 


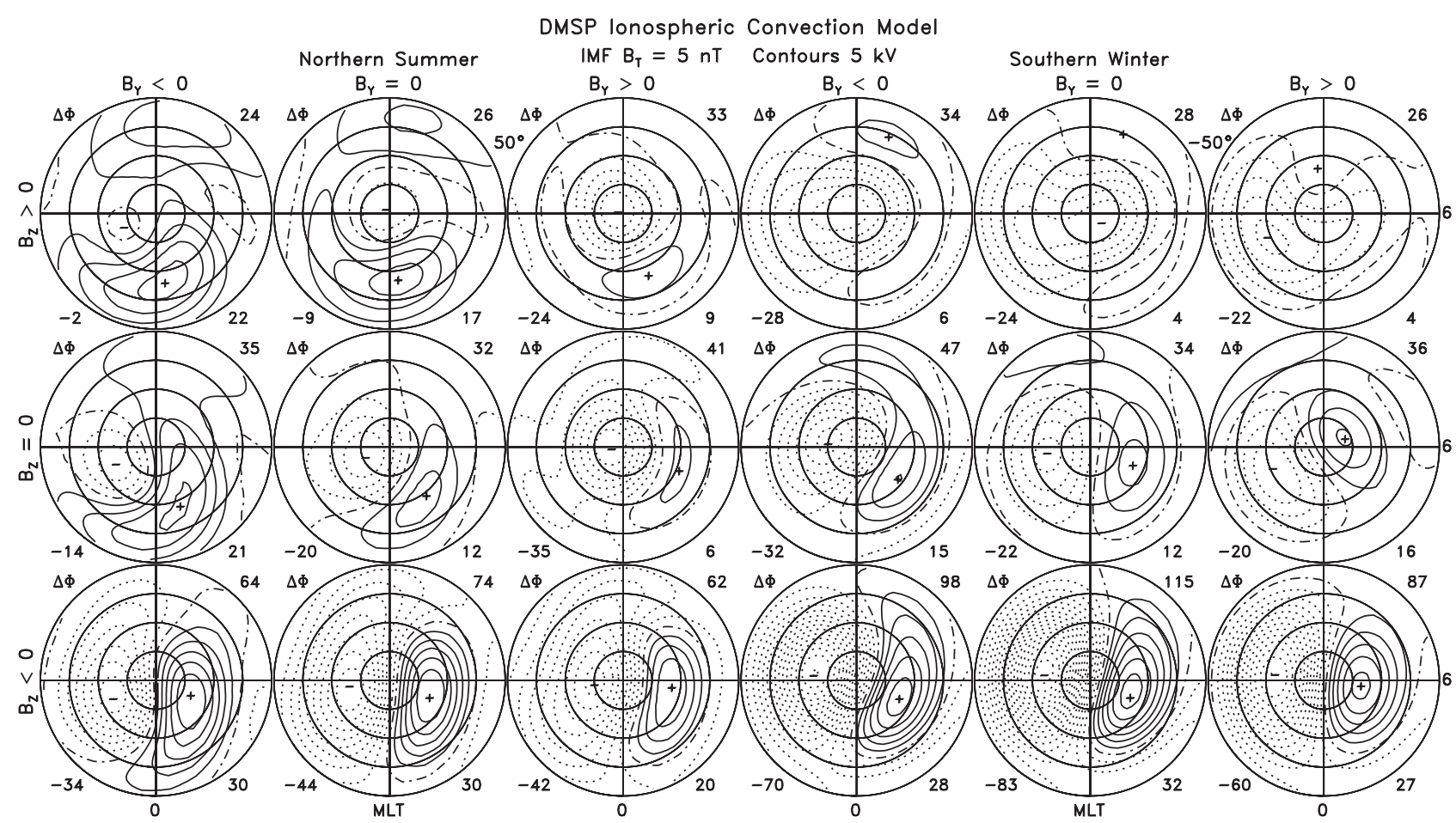

Figure 3. Same as in Figure 2 but for northern summer (left) and southern winter (right).

our Figure 1) but failed to clearly illustrate the model's IMF dependency by organizing the plots according to the certain IMF magnitude and clock angle. Nevertheless, over the years the IZMEM model was thoroughly tested and compared with various satellite data [e.g., Belov et al., 1984; Dremukhina et al., 1985, 1998; Feldstein et al., 1996], radar observations [Papitashvili et al., 1995; Kustov et al., 1997], and other available models [Winglee et al., 1997]. Papitashvili et al. [1999] recalibrated the ground magnetometerbased model IZMEM by the DMSP electrostatic potential observations; therefore the resulting IZMEM/DMSP model inherited the patterns' configuration from the ground mag-

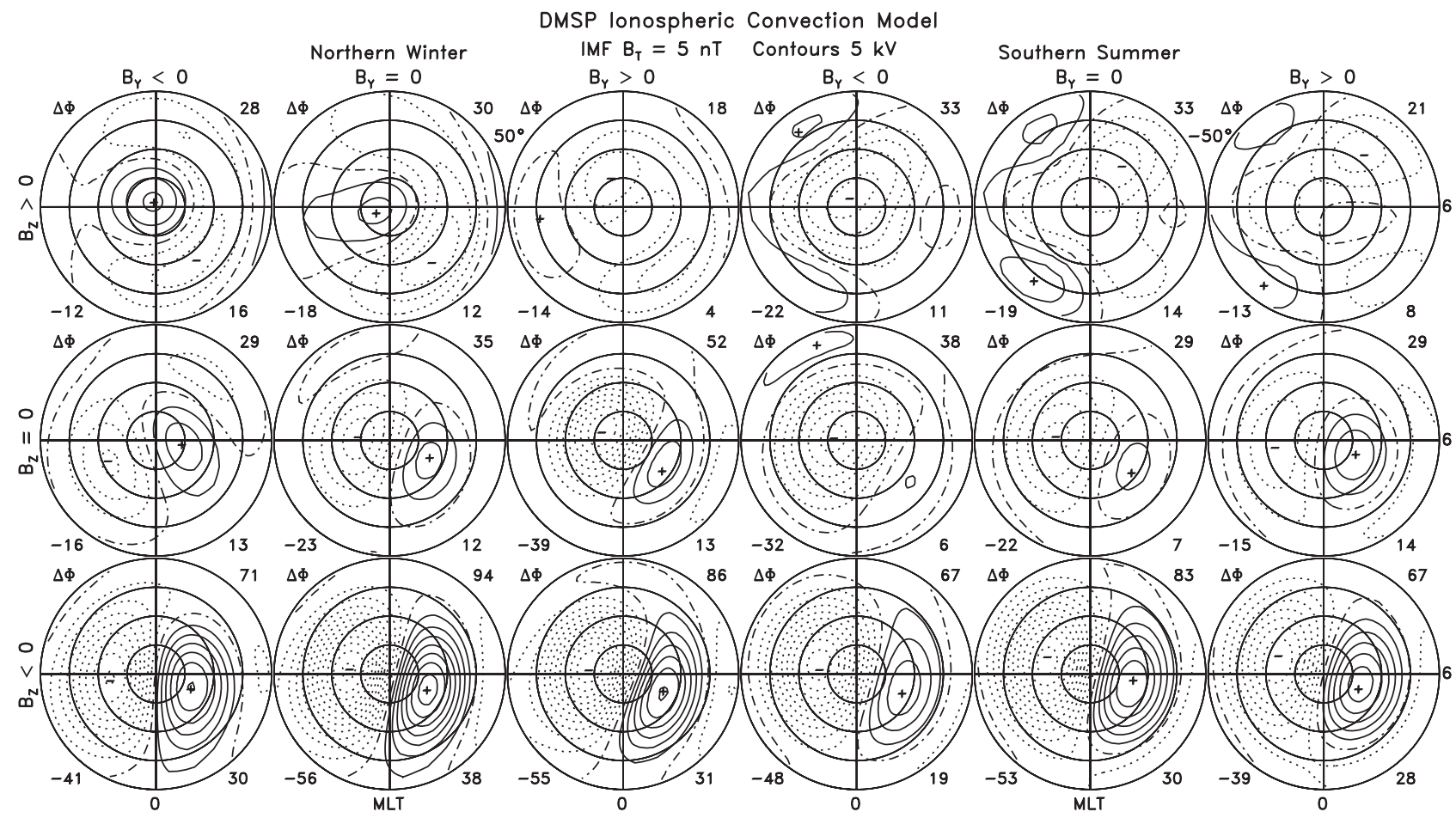

Figure 4. Same as in Figure 2 but for northern winter (left) and southern summer (right). 


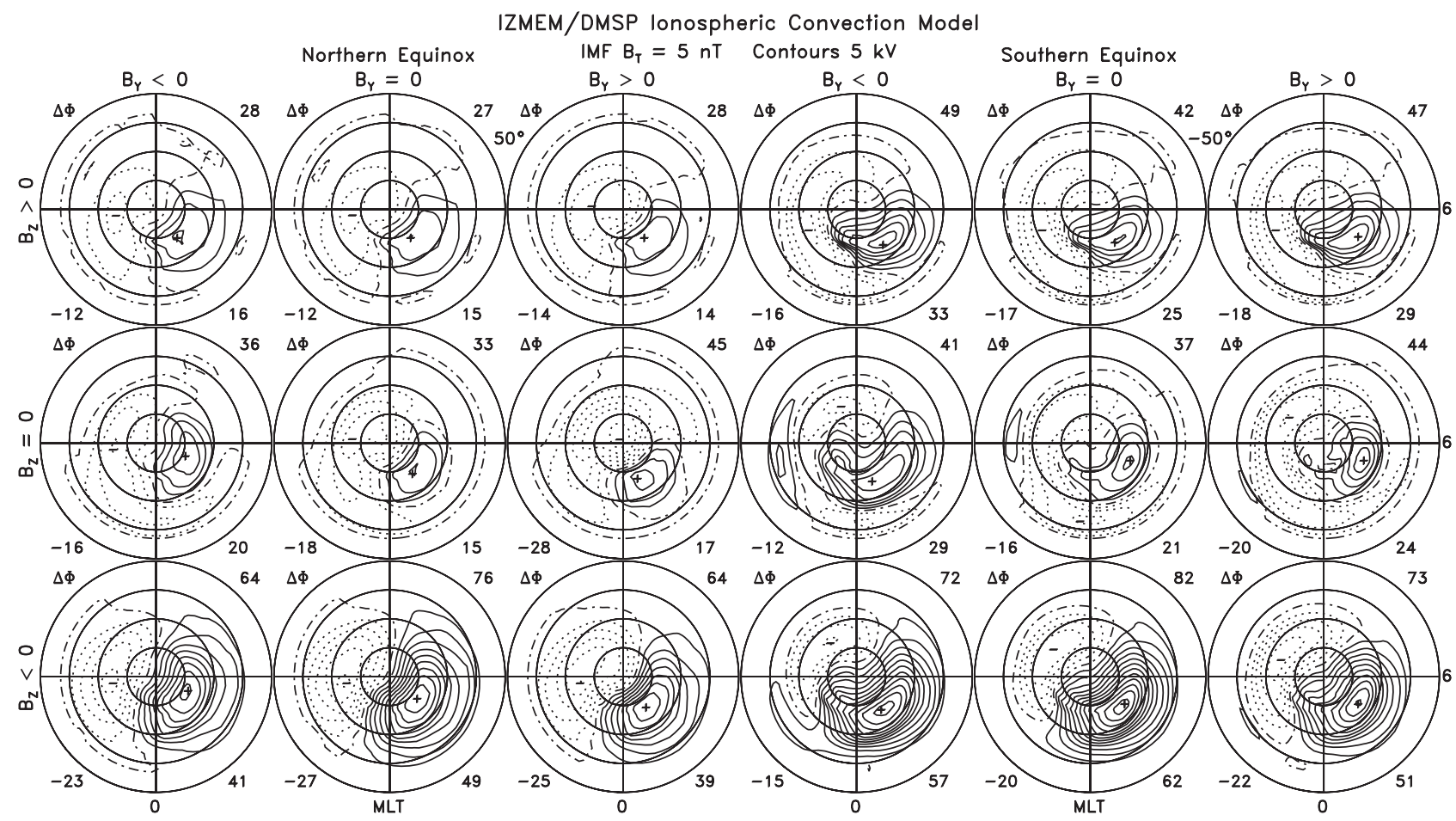

Figure 5. Contour plots of the IZMEM ground magnetometer model calibrated by the DMSP observations [Papitashvili et al., 1994, 1999]. The IMF-dependent high-latitude ionospheric convection patterns modeled for northern (left) and southern (right) equinoxes. The dial plots' organization and labels are the same as in Figure 2.

netometer data, but the newly calibrated model magnitudes are now more realistic.

[34] Figures 5-7 show the IZMEM/DMSP patterns modeled for $B_{T}=5 \mathrm{nT}$ and plotted in the same manner as Figures 2-4. Note that in the magnetograms inversion technique used in IZMEM a "zero potential" boundary condition is set at $\pm 57^{\circ} \mathrm{CGM}$ latitudes. The zero dash-dot contours are seen in Figures 5-7 plotted down to $\pm 50^{\circ}$ to make these figures comparable with the DICM plots in Figures 2-4.

[35] Figures 5-7 reveal that the IZMEM/DMSP background potentials do not show recognizable seasonal effect. The cross-polar reconnection $\left(B_{z}<0\right)$ potential increases from summer through equinox to winter in the Northern Hemisphere, but it goes in the opposite direction in the Southern Hemisphere. These potentials show better symmetry for the northern summer/southern winter and northern winter/southern summer pairs. Opposite to the results shown above for the DICM model, the dawn-dusk crosspolar potentials for the northward IMF show significant seasonal effect; the dawn-dusk potential drop increases from the summer to winter hemispheres. Seasonal effects are again inconclusive in the IMF $B_{y}$-controlled patterns. This model also shows that the dusk convection cell for IMF $B_{y}$ has 2-4 times more voltage than the dawn cell; however, here this is only a "summer" phenomenon, as shown by Crooker and Rich [1993].

[36] Thus the ground-based magnetometer model IZMEM, calibrated by the DMSP observations, does show less significant seasonal effects than the DMSP satellitebased model DICM. This result is quite surprising because
IZMEM uses the statistical ionospheric conductivity model by Wallis and Budzinski [1981]; therefore it assumes seasonal changes in the conductivities. On the other hand, DICM is a purely $F$-layer model ( $\sim 840 \mathrm{~km}$ altitude), but it shows some seasonal effects. We hypothesize below that this is possibly caused by the seasonal dependence of the field-aligned currents [e.g., Fuiji et al., 1981; Christiansen et al., 2002], which close the mapped cross-polar potential over both polar ionospheres.

\section{Discussion}

[37] Tables 1a-1c summarizes the cross-polar potentials for most of the IMF clock-angle patterns presented in this study, addressing the background $\left(B_{T} \approx 0\right)$ and purely southward, northward, or azimuthal IMF-controlled potentials, i.e., for $\left|B_{z}\right|=5 \mathrm{nT}$ and $\left|B_{y}\right|=5 \mathrm{nT}$. In addition, we listed the cross-polar potentials inferred from some other known models where the data or patterns were organized by the IMF clock angle for $B_{T} \approx 5 \mathrm{nT}$. The first three models (Danish Meteorological Institute (DMI), IZMEM, and IZMEM/DMSP) are based on ground magnetometer data. The next three models (DICM, DMSP, and DE2) are based on satellite data. The last model APL (Applied Physics Laboratory, Johns Hopkins University) is based on HF radar data. Thus this table allows us to compare the cross-polar potentials obtained from different data sources and utilized different techniques. We would include in Table 1 a number of other models for comparison [e.g., Heelis et al., 1982; Foster, 1983; Heppner and Maynard, 1987; Holt et al., 1987; Hairston and Heelis, 1990; Peymirat and Fontaine, 


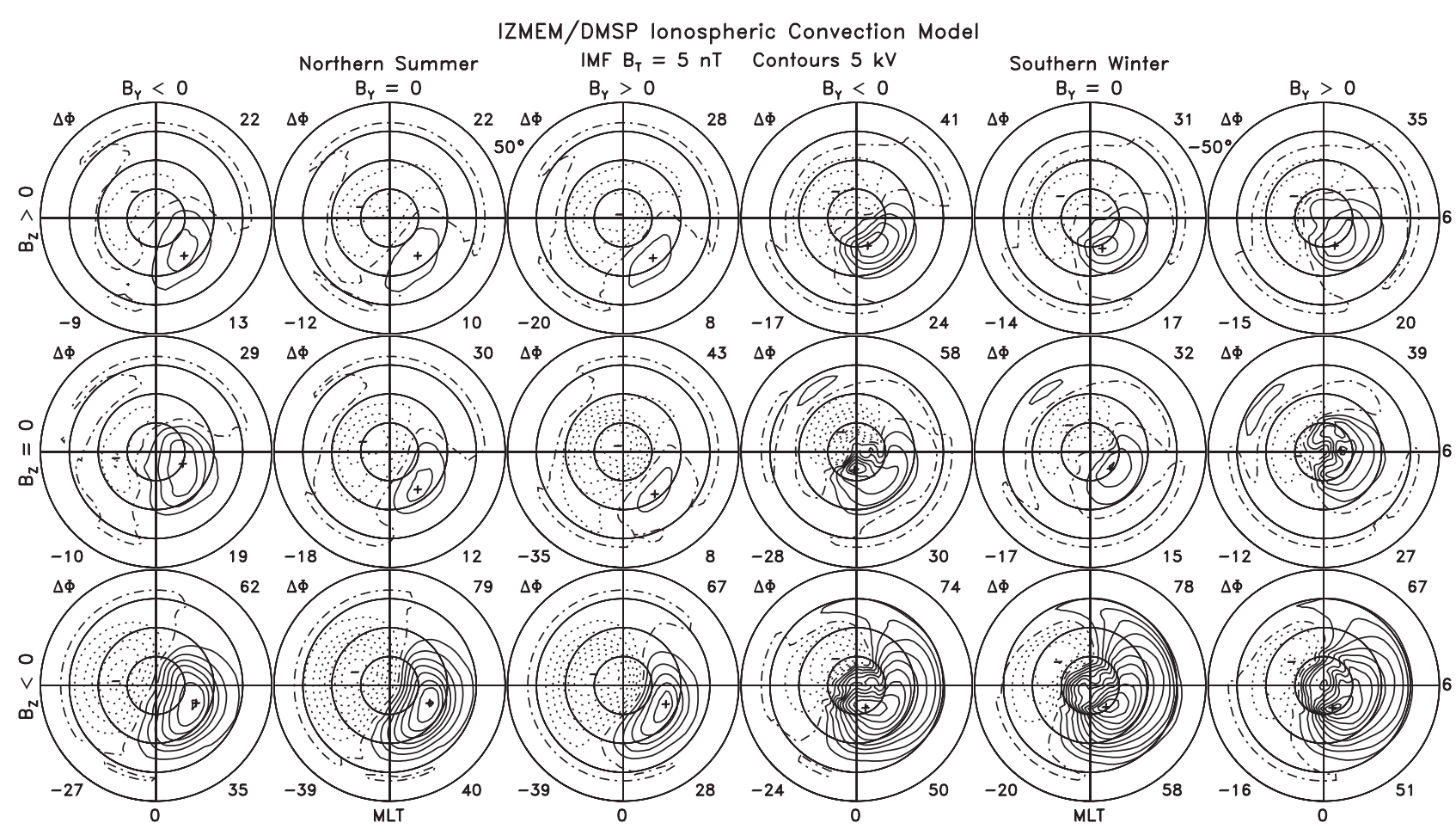

Figure 6. Same as in Figure 5 but for northern summer (left) and southern winter (right).

1997], but these models either are not organized by the IMF clock angle or are not clearly organized by the IMF magnitude.

[38] We averaged the dawn-dusk cross-polar potentials for all listed models to see if there is any recognizable seasonal effect in the averaged numbers and to estimate (from the standard deviation $\sigma$ ) the models' scatter. The averaging worked fairly well, producing comparable numbers with reasonable standard deviations. All average crosspolar potentials show a weak seasonal effect; the potential drops generally increase from summer to winter. The standard deviation varies, but in general, it is $\sim 20 \%$ of the

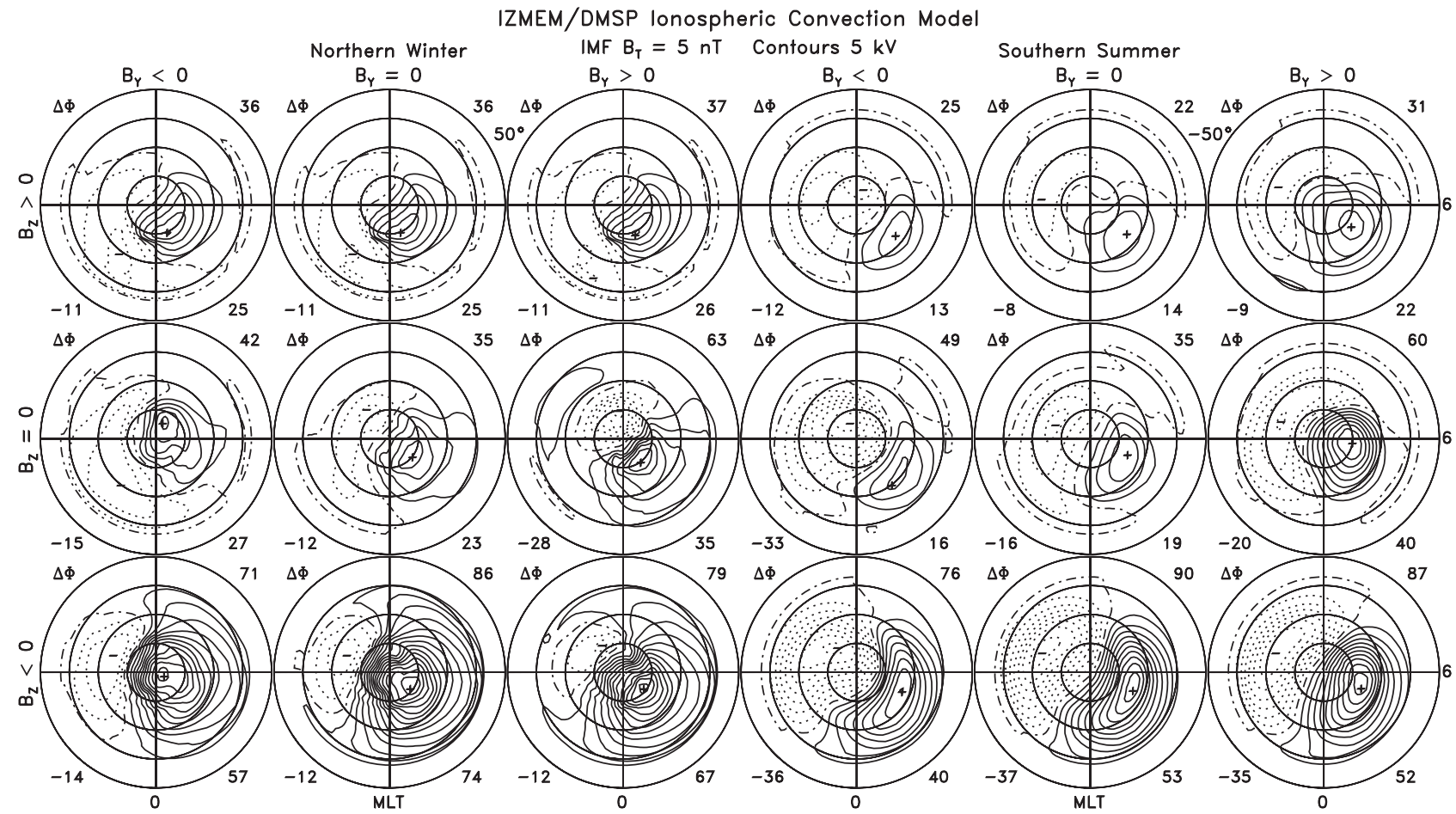

Figure 7. Same as in Figure 5 but for northern winter (left) and southern summer (right). 
Table 1a. Comparison of Cross-Polar Potentials Derived from the Background $\left(B_{T} \approx 0\right)$, Southward, Northward, and Azimuthal IMF Patterns $\left(B_{T} \approx 5 \mathrm{nT}\right)$ of Various IMF-Dependent High-Latitude Ionospheric Convection Models for Summer ${ }^{\mathrm{a}}$

\begin{tabular}{|c|c|c|c|c|c|c|}
\hline Reference & Hemisphere & $B_{T} 0$ & $B_{z}-$ & $B_{z}+$ & $B_{y}-$ & $B_{y}+$ \\
\hline $\mathrm{DMI}^{\mathrm{b}}$ & $\mathrm{N}$ & 35 & 60 & 28 & 49 & 43 \\
\hline \multirow[t]{2}{*}{ IZMEM $^{\mathrm{c}}$} & $\mathrm{N}$ & 29 & 94 & 26 & 31 & 46 \\
\hline & $\mathrm{S}$ & 41 & 83 & 22 & 58 & 59 \\
\hline \multirow[t]{2}{*}{ IZMEM/DMSP $^{\mathrm{d}}$} & $\mathrm{N}$ & 30 & 79 & 22 & 29 & 43 \\
\hline & $\mathrm{S}$ & 35 & 90 & 22 & 49 & 60 \\
\hline \multirow[t]{2}{*}{$\mathrm{DICM}^{\mathrm{e}}$} & $\mathrm{N}$ & 32 & 74 & 26 & 35 & 41 \\
\hline & $\mathrm{S}$ & 29 & 83 & 33 & 38 & 29 \\
\hline $\mathrm{DMSP}^{\mathrm{f}}$ & $\mathrm{N}$ and $\mathrm{S}$ & & 77 & 21 & 42 & 35 \\
\hline $\mathrm{DE} 2^{\mathrm{g}}$ & $\mathrm{N}$ and $\mathrm{S}$ & & 78 & 34 & 55 & 56 \\
\hline $\mathrm{APL}^{\mathrm{h}}$ & $\mathrm{N}$ & & & & & \\
\hline Average value & & 33 & 87 & 26 & 43 & 46 \\
\hline$\pm \sigma$ & & \pm 4 & \pm 12 & \pm 5 & \pm 10 & \pm 10 \\
\hline
\end{tabular}

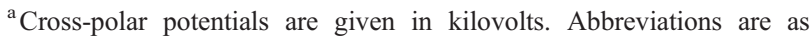
follows: DMI, Danish Meterological Institue; IZMEM, Institute of Terrestrial Magnetism, Ionosphere, and Radio Wave Propagation (Russian Academy of Sciences) electrodynamic model; DMSP, Defense Meteorological Satellite Program; APL, Applied Physics Laboratory model.

${ }^{\mathrm{b}}$ From Friis-Christensen et al. [1985].

${ }^{\mathrm{c}}$ From Papitashvili et al. [1994].

${ }^{\mathrm{d}}$ From Papitashvili et al. [1999].

${ }^{\mathrm{e}}$ From this study.

${ }^{\mathrm{f}}$ From Rich and Hairston [1994].

${ }^{\mathrm{g}}$ From Weimer [1995].

${ }^{\mathrm{h}}$ From Ruohoniemi and Greenwald [1996].

corresponding average value. First, we note that the DMI model, which is available only for the northern summer, shows most of its parameters close to the averaged values; only the reconnection cross-polar potential $\left(B_{z}<0\right)$ is below the average value by $\sim 30 \%$. The model IZMEM produces estimates of almost all presented potentials above the average values by $\sim 10-20 \%$. As discussed by Papitashvili et al. [1994], this is not surprising because of certain difficulties which had to be overcome in the model calibration without using the satellite data. By calibrating the IZMEM model with the DMSP observations, the IZMEM/ DMSP model shows better comparisons with other models, as well as with the average values shown in the bottom row of Table 1.

[39] The next series of three models show the cross-polar potentials inferred from satellite data. Here we note that even the DMSP patterns [Rich and Hairston, 1994], where the data were contoured by hands, show cross-polar potentials which compare very well with the fully IMF-parameterized model DICM. Also, the DICM values compare

Table 1b. Same as Table 1a Except for Equinox

\begin{tabular}{lcrrrrr}
\hline \multicolumn{1}{c}{ Reference } & Hemisphere & $B_{T} 0$ & $B_{z}-$ & $B_{z}+$ & $B_{y}-$ & $B_{y^{+}}$ \\
\hline DMI & $\mathrm{N}$ & & & & & \\
IZMEM & $\mathrm{N}$ & 42 & 109 & 39 & 46 & 62 \\
& $\mathrm{~S}$ & 25 & 83 & 20 & 36 & 34 \\
IZMEM/DMSP & $\mathrm{N}$ & 33 & 76 & 27 & 36 & 45 \\
& $\mathrm{~S}$ & 37 & 82 & 42 & 41 & 44 \\
DICM & $\mathrm{N}$ & 31 & 79 & 11 & 33 & 40 \\
& $\mathrm{~S}$ & 35 & 88 & 14 & 45 & 33 \\
DMSP & $\mathrm{N}$ and S & & & & & \\
DE2 & $\mathrm{N}$ and S & & 89 & 29 & 55 & 59 \\
APL & $\mathrm{N}$ & & 68 & 18 & 43 & 45 \\
Average value & & 34 & 84 & 25 & 42 & 45 \\
$\pm \sigma$ & & \pm 5 & \pm 11 & \pm 10 & \pm 7 & \pm 11 \\
\hline
\end{tabular}

Table 1c. Same as Table 1a Except for Winter

\begin{tabular}{lcrrrrc}
\hline \multicolumn{1}{c}{ Reference } & Hemisphere & $B_{T} 0$ & $B_{z}-$ & $B_{z}+$ & $B_{y}-$ & $B_{y}+$ \\
\hline DMI & $\mathrm{N}$ & & & & & \\
IZMEM & $\mathrm{N}$ & 42 & 92 & 21 & 43 & 70 \\
& $\mathrm{~S}$ & 46 & 109 & 42 & 80 & 54 \\
IZMEM/DMSP & $\mathrm{N}$ & 35 & 86 & 36 & 42 & 63 \\
& $\mathrm{~S}$ & 32 & 78 & 31 & 58 & 39 \\
DICM & $\mathrm{N}$ & 35 & 94 & 30 & 29 & 52 \\
& $\mathrm{~S}$ & 34 & 115 & 28 & 47 & 36 \\
DMSP & $\mathrm{N}$ and S & & & & & \\
DE2 & $\mathrm{N}$ and S & & 78 & 20 & 46 & 53 \\
APL & $\mathrm{N}$ & & 68 & 18 & 43 & 45 \\
Average value & & 37 & 90 & 28 & 48 & 52 \\
$\pm \sigma$ & & \pm 5 & \pm 15 & \pm 8 & \pm 14 & \pm 11 \\
\hline
\end{tabular}

well with the average numbers at the bottom row of Table 1 . Both the new DICM and old DMSP models compare well with the numbers from the DE2 model developed by Weimer [1995].

[40] An approach similar to Weimer's approach was utilized by Ruohoniemi and Greenwald [1996] in their attempt to construct the APL ionospheric convection model based on the Goose Bay HF radar data taken from September 1987 to June 1993. From the time intervals used we only can refer this model to the equinox and winter times. The APL model shows the lower cross-polar potentials in comparison with Weimer's DE2 model, but it shows better comparisons with the DICM and average values in the bottom row of Table 1 .

[41] Now what are the implications of the presented interhemispheric studies of seasonal effects in the crosspolar potentials for the solar wind-magnetosphere-ionosphere (SWMI) coupling? According to a review by Reiff and Luhmann [1986], the SWMI coupling is thought to be a one-way linear process that taps a fraction of the solar wind potential across the magnetosphere through magnetic reconnection and therefore yields a magnetospheric convection potential $\Phi_{m}$. The latter maps down (along equipotential geomagnetic field lines) to the polar ionosphere as a crosspolar potential $\Phi_{p c}$ that generates region 1 field-aligned currents. However, it was also known from observations that $\Phi_{p c}$ saturates at and above $\sim 200 \mathrm{kV}$. Siscoe et al. [2002] reported that the Hill's SWMI coupling model provides a feedback from the ionosphere to the magnetosphere through the voltage-current relation, where $\Phi_{p c}$ is controlled by the varying strength of R1 currents,

$$
\Phi_{p c}=\Phi_{m}-\left(\Phi_{m} / J_{\mathrm{R} 1 \max }\right) J_{\mathrm{R} 1} .
$$

Here $J_{\mathrm{R} 1 \max }$ is the "saturating" R1 current (generated by the SWMI coupling) of such strength that its magnetic effect (directed southward at the subsolar point) begins to weaken the geomagnetic field at the dayside magnetopause, canceling any further increases of $\Phi_{m}$ and saturating $\Phi_{p c}$ $\rightarrow \Phi_{\mathrm{R} 1 \max }$. Therefore $\Phi_{m} / J_{\mathrm{R} 1 \max }$ in equation (3) quantifies the effect that actual R1 currents $J_{\mathrm{R} 1}=\xi \Sigma_{P} \Phi_{p c}$ have in regulating the amount of $\Phi_{p c}$ tapped from $\Phi_{m}$ to the polar caps (here $\Sigma_{P}$ is the cross-polar Pedersen conductivity and $\xi$ is the R1 geometry coefficient). Evaluating equation (3) through the typical IMF and solar wind parameters $E_{\mathrm{SW}}=$ $-V_{\mathrm{SW}} \times B_{\mathrm{IMF}}=(350 \mathrm{~km} / \mathrm{s} \times 5 \mathrm{nT}) \times 10^{-3}=1.75 \mathrm{mV} / \mathrm{m}$ and $p_{\mathrm{SW}}=1 \mathrm{nPa}$ for the purely southward IMF, Siscoe et al. [2002] reduced equation (3) to the following voltage-current 
relation which they used for comparisons with the results of their MHD simulations,

$$
\Phi_{p c}(k V)=101-21.8 J_{\mathrm{R} 1}(M A) .
$$

[42] It seems that in equation (3) the magnetic effect of $\mathrm{R} 1$ currents at the magnetopause is combined from both current loops existed in the Northern and Southern Hemispheres. We may guess that during equinox the R1 currents of the same intensity flow in both loops. However, from a recent study by Christiansen et al. [2002] we know that the dawn-dusk R1 field-aligned currents are 1.5 times stronger in the summer polar cap in comparison with the winter currents, i.e., $J_{\mathrm{R} 1 s} / J_{\mathrm{R} 1 w}=1.5$; this is also seen indirectly in the maps of field-aligned currents recently obtained by Weimer [2001b] and Papitashvili et al. [2002]. Therefore we tried to draw a cartoon, where we considered two possible configurations of the dayside magnetopause affected by the combined magnetic effect of $\mathrm{R} 1$ currents during equinox and summer/winter.

[43] Figure 8 shows the equinoctial "symmetric" scenario, where the magnetopause (solid line) moves slightly inward (dashed line) or outward as the intensity of R1 currents varies simultaneously in both polar regions due to variations in the IMF/SW conditions (we note that these magnetopause variations happen all the time, even if $J_{\mathrm{R} 1} \ll$ $\left.J_{\mathrm{R} 1 \text { max }}\right)$. Here the length of a reconnection line determines $\Phi_{p c}$, which is equally applied across both the northern and southern polar caps. However, as we wish to consider the summer/winter conditions (Figure 8), we simply increase the intensity of R1 currents in the "summer" hemisphere (which happens when the northern pole of Earth's dipole tilts toward the Sun). Now the combined magnetic effects of both the northern and southern R1 loops becomes asymmetric, producing a bulge in the "winter" half of the dayside magnetopause, like the nose of a commercial jet aircraft. Here a reconnection line either shifts (at this plot) below the equatorial plane, or it may become a crescent-like band aligned along the ("aircraft nose") flank. In the former case the same magnetospheric potential $\Phi_{m}$ is still applied to both polar regions, but the hypothetical finite resistance of magnetospheric field lines may cause different "along-theline" potential drops to the northern and southern polar ionospheres [e.g., Siscoe et al., 2001]. In the latter case we hypothesize that the crescent-like reconnection band may have internal resistance providing slightly different $\Phi_{p c s}<$ $\Phi_{p c w}$ to the northern and southern polar caps. In any case, this difference in the cross-polar potentials should be small because we do not expect a significant change in the topological properties of the dayside magnetopause.

[44] If we take $J_{\mathrm{R} 1 w}=1.0 \mathrm{MA}$ for the winter loop and $J_{\mathrm{R} 1 s}=1.5 \mathrm{MA}$ for the summer loop and enter these values in equation (4), we will obtain the summer-to-winter ratio for the cross-polar potentials $\Phi_{\text {summer }} / \Phi_{\text {winter }}=0.86$. This value matches very well with the corresponding summerto-winter ratios calculated from the average cross-polar potentials shown in Table 1 or from the numbers obtained in our new DICM model. For example, DICM produces for $B_{z}=-5 \mathrm{nT}$ the northern-summer/southern-winter ratio 0.64 , and the southern-summer/northern-winter ratio 0.88 . However, here we should note that the northern/ southern equinoctial ratio in DICM amounts to 0.90 . We
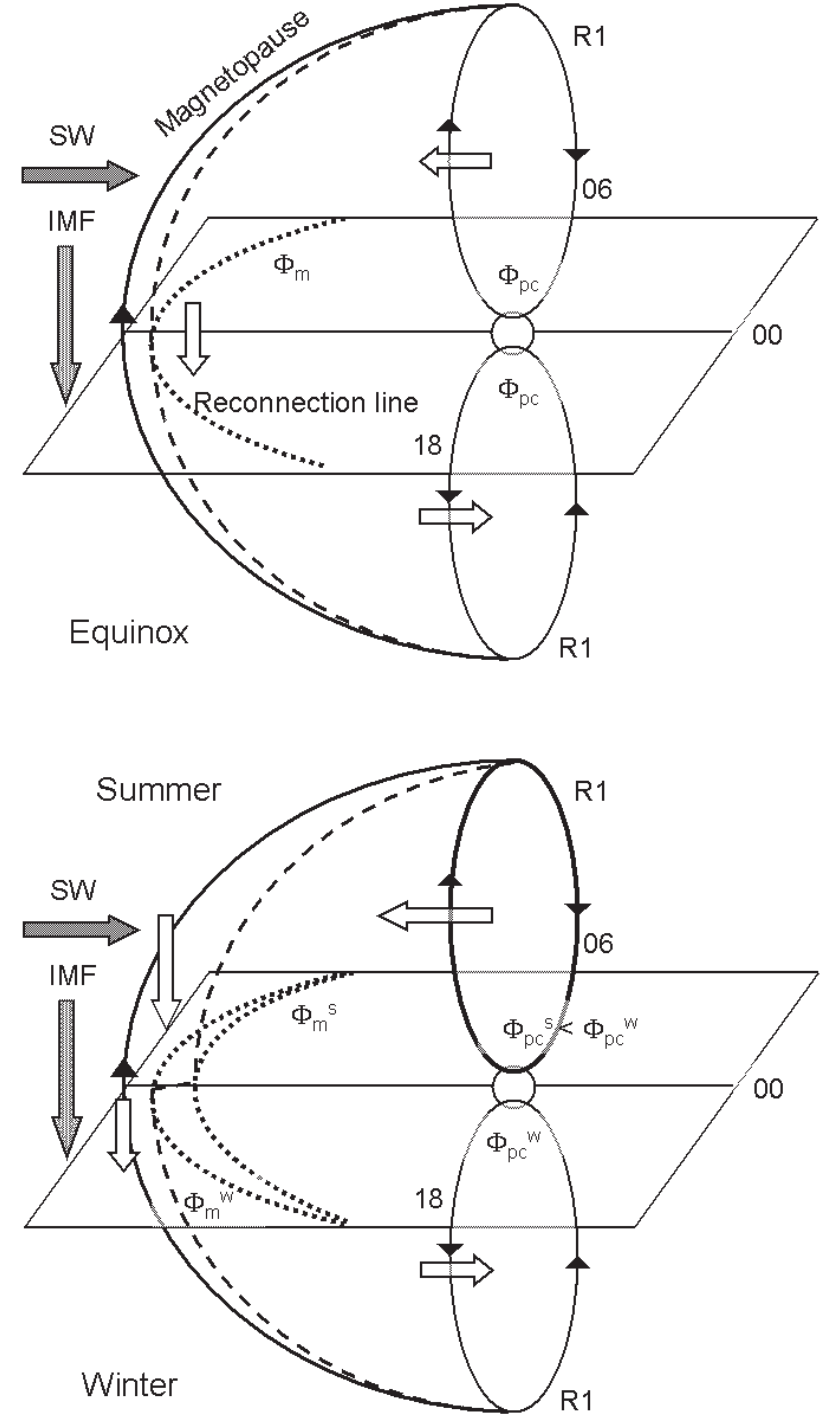

Figure 8. A cartoon explanation of the R1 magnetic effects at the dayside magnetopause (see section 4 for details).

only can refer this difference to the possible northern/ southern asymmetry imbedded geometrically in the R1 loops configurations because Christiansen et al. [2002] firmly showed that there is no difference in the equinoctial R1 currents flowing into the northern and southern polar caps, i.e., $J_{\mathrm{R} 1 \mathrm{NE}} / J_{\mathrm{R} 1 \mathrm{SE}}=1.0$, where $\mathrm{NE}$ and $\mathrm{SE}$ are the northern equinox and southern equinox, respectively. Nevertheless, if we take the obtained equinoctial asymmetry in the cross-polar potentials as given and correct the DICM summer and winter numbers for the equinoctial effect, then the northern summer (NS)/southern winter (SW) ratio increases to 0.71 , and the southern summer (SS)/northern winter (NW) ratio increases to 0.90. Siscoe et al. [2002] show in their Table 1 that increasing the Pedersen conductance $\Sigma$ from 2.0 to $6.0 \mathrm{~S}$ (which can be considered as the approximately correct changes for the polar cap from winter to summer), the MHD simulations give an increase of $J_{\mathrm{R} 1}$ from $0.74 \mathrm{MA}$ to $1.5 \mathrm{MA}$, i.e., $J_{\mathrm{R} 1 s} / J_{\mathrm{R} 1 w}=2.0$. Through equation (4) they obtain the 
corresponding decrease in $\Phi_{p c}$ from 87.7 to $70.5 \mathrm{kV}$ $\left(\Phi_{\text {summer }} / \Phi_{\text {winter }}=0.80\right)$.

[45] Thus in this study the DICM winter cross-polar potentials are $10-15 \%$ larger than the summer potentials for the southward IMF. This also implies that R1 fieldaligned currents flowing into the summer polar cap are 1.5 times stronger, as obtained from the Ørsted satellite observations. Although we may suggest that this difference in the cross-polar potentials could be caused by the limited accuracy of our modeling, we also may hypothesize that some differences could be caused by the interhemispheric asymmetry of the three-dimensional R1 current system providing a feedback to the dayside reconnection. We note again that all above mentioned DICM numbers scatter near the ratio obtained from equation (4). Therefore we may ask: Is this a coincidence or reality? We conclude that more studies are needed to resolve this question.

\section{Conclusions}

1. We believe that all currently available ground- or satellite-based ionospheric convection models, somehow parameterized by the IMF strength and/or direction, show comparable responses of the high-latitude ionosphere on changes in the IMF and solar wind near Earth's orbit. However, the LIMIE approach used for construction of the ground magnetometer-based models, and now for the DICM study, is the only one that explicitly described the background (quasi-viscous) convection patterns for both polar regions and all seasons, independent of the IMF strength and direction. This approach also provides a quantified response of the high-latitude ionospheric convection on continuous changes in the IMF over the entire polar area in the form of "basic convection cells" related to the corresponding IMF component. Then the "building blocks" (the background two-cell pattern, the $B_{y}$-controlled lobe cell, and the reconnection $\left(B_{z}<0\right)$ or reverse $\left(B_{z}>0\right)$ two-cell convection) can be used for easy construction of the resulting (for certain IMF conditions) convection pattern for the specific season and over both the northern or southern polar regions. We note that DICM is not intended for modeling major magnetic storm events because it was developed for the quasi-steady, quasinormal conditions. Different studies are needed for the storm-time conditions.

2. The new DMSP-based model of ionospheric convection shows firmly that there is a persistent dawn-dusk asymmetry in the standard two-cell convection patterns against the noon-midnight meridian. The dusk cell dominates in the background potential patterns (controlled, as thought, by the quasi-viscous processes), causing the recognizable asymmetry in all subsequent patterns when the IMF $B_{z^{-}}$or $B_{y}$-controlled patterns are added. We guess that this asymmetry might be caused by the hemispheric bias in inferring the along-the-track potentials from the DMSP ion drift measurements; therefore, this feature needs further attention and study for the conditions when $\mathrm{IMF} \approx 0$.

3 . The voltage ratio of $\sim 0.85$ between the summer and winter cross-polar potentials, obtained in our study, matches very well with the Ørsted-based study of seasonal effects in the $\mathrm{R} 1$ currents $\left(J_{\mathrm{R} 1 s} / J_{\mathrm{R} 1 w}=1.5\right)$ [Christiansen et al., 2002;
Papitashvili et al., 2002]. This is in good agreement with the voltage-current relation derived by Siscoe et al. [2002] from the physics-based model of the solar wind-magnetosphere-ionosphere coupling and justified by the corresponding MHD simulations.

4. In addition, the hemispheric cross-polar potentials are slightly asymmetric even during equinox, $\Phi_{N E} / \Phi_{S E}=$ 0.9 . This result requires that the $\mathrm{R} 1$ field-aligned currents may not be supplied equally to both polar regions due to the interhemispheric geometrically imbedded asymmetry in the overall configuration of the main geomagnetic field and the magnetospheric field sources. Variations in the ionospheric conductivity may also contribute to this effect.

5. The DICM patterns do not depend on any assumptions about the ionospheric conductivities; however, the ionospheric convection patterns obtained via the use of the magnetograms inversion technique depend heavily on these assumptions. Although it is almost obvious that the groundbased radars and digisondes observations should also be free of the ionospheric conductivity assumptions, the study of these models should proceed with a certain caution, checking properly the voltage-current relationships and comparing results with other available models of ionospheric convection.

6. At last, the results presented in this study justify a need in developing a unified approach for the modeling of highaltitude ionospheric convection from various sources (i.e., ground magnetometers, radars, digisondes, and satellite observations; if we can be sure of the instrumental cross calibration). This may lead to a unified ionospheric convection model fully parameterized by the IMF strength and direction, as well as the solar wind velocity and density, allowing seamless data assimilation in various "space weather" case studies.

[46] IZMEM, IZMEM/DMSP, and DICM models are available and can be run online via the SPRL World Wide Web site http://www.sprl.umich.edu/mist/limie.html.

[47] Acknowledgments. We thank Mark R. Hairston of the University of Texas at Dallas and Boris A. Belov of IZMIRAN for providing computer codes used for derivation of electrostatic potentials from DMSP ion drifts and for the spherical harmonic analysis, respectively. Discussions on the solar wind-magnetosphere-ionosphere coupling with Gary M. Erickson and George L. Siscoe of Boston University and William J. Burke of AFRL are also appreciated. We thank National Science Data Center for making the IMF OMNI data available via the World Wide Web. This work was made possible by funding from the NRC/AFOSR 2001 Summer Faculty Fellowship (V.O.P.) and under the AFOSR Task 2311 G5 (F.J.R.). In addition, the study was partially supported at Michigan by the NSF awards OPP9614175, ATM-9727554, and DoD AFOSR F49620-01-1-0359.

[48] Janet G. Luhmann thanks both referees for their assistance in evaluating this paper.

\section{References}

Afonina, R. G., B. A. Belov, A. E. Levitin, M. Y. Markova, Y. I. Feldstein, and M. V. Fiskina, Connection of components of the interplanetary magnetic field with field-aligned currents at high-latitudes of the Northern Hemisphere, Geomagn. Aeron., 20, 1073, 1980.

Barton, C. E., International Geomagnetic Reference Field: The seventh generation, J. Geomag. Geoelectr., 49, 123, 1997.

Belov, B. A., R. G. Afonina, A. E. Levitin, and Y. I. Feldstein, The effects of interplanetary magnetic field orientation on geomagnetic field in the northern polar cap (in Russian), in Variations of Magnetic Field and the Aurora, edited by Y. I. Feldstein and A. E. Levitin, p. 15, Inst. Terr. Magn. Ionos. Radiowave Propag., Moscow, 1977. 
Belov, B. A., Y. I. Galperin, L. V. Zinin, A. E. Levitin, R. G. Afonina, and Y. I. Feldstein, Plasma convection in the polar ionosphere: A comparison of the satellite Cosmos-184 measurements and the model related to the IMF vector, Space Res., 22, 201, 1984.

Burke, W. J., D. R. Weimer, and N. C. Maynard, Geoeffective interplanetary scale sizes derived from regression analysis of polar cap potentials, J. Geophys. Res., 104, 9989, 1999.

Christiansen, F., V. O. Papitashvili, and T. Neubert, Seasonal variations of high-latitude field-aligned current systems inferred from Ørsted and Magsat observations, J. Geophys. Res., 107, 10.1029/2001JA900104, 2002.

Crooker, N. U., Reverse convection, J. Geophys. Res., 97, 19,363, 1992.

Crooker, N. U., and F. J. Rich, Lobe cell convection as a summer phenomenon, J. Geophys. Res., 98, 13,403, 1993.

Dremukhina, L. A., Y. I. Feldstein, and A. E. Levitin, Model calculations of currents and magnetic fields along a MAGSAT trajectory, J. Geophys. Res., 90, 6657, 1985.

Dremukhina, L. A., A. E. Levitin, and V. O. Papitashvili, Analytical representation of IZMEM model for near-real time prediction of electromagnetic weather, J. Atmos. Sol. Terr. Phys., 60, 1517, 1998.

Feldstein, Y. I., and A. E. Levitin, Solar wind control of electric fields and currents in the ionosphere, J. Geomagn. Geoelectr., 38, 1143, 1986.

Feldstein, Y. I., A. E. Levitin, D. S. Faermark, R. G. Afonina, B. A. Belov, and V. Y. Gaidukov, Electric fields and potentials in the high-latitude ionosphere for different situations in the interplanetary space, Planet. Space Sci., 32, 907, 1984.

Feldstein, Y. I., L. I. Gromova, A. E. Levitin, L. G. Blomberg, G. T. Marklund, and P.-A. Lindquist, Electromagnetic characteristics of the high-latitude ionosphere during the various phases of magnetic substorms, J. Geophys. Res., 101, 19,921, 1996.

Foster, J. C., An empirical electric field model derived from Chatanika radar data, J. Geophys. Res., 88, 981, 1983.

Friis-Christensen, E., and J. Wilhjelm, Polar cap currents for different directions of the interplanetary magnetic field in the $Y-Z$ plane, J. Geophys Res., 80, 1248, 1975.

Friis-Christensen, E., Y. Kamide, A. D. Richmond, and S. Matsushita, Interplanetary magnetic field control of high-latitude electric field and currents determined from Greenland magnetometer data, J. Geophys. Res., 90, 1325, 1985.

Fujii, R., T. Iijima, T. A. Potemra, and M. Sugiura, Seasonal dependence of large-scale Birkeland currents, Geophys. Res. Lett., 8, 1103, 1981.

Hairston, M. R., and R. A. Heelis, Model of high-latitude ionospheric convection pattern during southward interplanetary magnetic field using DE 2 data, J. Geophys. Res., 95, 2333, 1990.

Hairston, M. R., and R. A. Heelis, High-latitude electric field studies using DMSP data, Rep. PL-TR-93-2036, 45 pp., Air Force Phillips Lab., Hanscom Air Force Base, Mass., 1993.

Heelis, R. A., J. K. Lowell, and R. W. Spiro, A model of the high-latitude ionospheric convection pattern, J. Geophys. Res., 87, 6339, 1982.

Heppner, J. P., and N. C. Maynard, Empirical high-latitude electric field models, J. Geophys. Res., 92, 4467, 1987.

Holt, J. M., R. H. Wand, J. V. Evans, and W. L. Oliver, Empirical models for the plasma convection at high latitudes from Millstone Hill observations, J. Geophys. Res., 92, 203, 1987.

Kamide, Y., A. D. Richmond, and S. Matsushita, Estimation of ionospheric electric fields, ionospheric currents and field-aligned currents from ground magnetic records, J. Geophys. Res., 86, 801, 1981.

King, J. H., and N. E. Papitashvili, Interplanetary Medium Data Book, Supplement 5, 1988-1993, NSSDC/WDC-A-R\&S 94-08, Natl. Space Sci. Data Cent., NASA Goddard Space Flight Center, Greenbelt, Md., 1994.

Kustov, A. V., et al., Dayside ionospheric plasma convection, electric fields, and field-aligned currents derived from the SuperDARN radar observations and predicted by the IZMEM model, J. Geophys. Res., 102, 24,057, 1997.

Langel, R. A., The main geomagnetic field, in Geomagnetism, vol. 1, edited by J. A. Jacobs, chap. 4, Academic, San Diego, Calif., 1991.

Levitin, A. E., R. G. Afonina, B. A. Belov, and Y. I. Feldstein, Geomagnetic variations and field-aligned currents at northern high-latitudes and their relations to solar wind parameters, Philos. Trans. R. Soc. London, Ser. A, 304, 253, 1982

Mansurov, S. M., O. A. Troshichev, A. N. Zaitzev, V. O. Papitashvili, G. A. Timofeev, and M. A. Kandibolotskaya, Characteristics of magnetic disturbances produced by the IMF in the southern polar cap, Geomagn Aeron., 21, 428, 1981.

Papitashvili, V. O., O. A. Troshichev, and A. N. Zaitzev, Linear dependence of the intensity of geomagnetic variations in the polar region on the magnitudes of the southern and northern components of the interplanetary magnetic field, Geomagn. Aeron., 21, 565, 1981

Papitashvili, V. O., Y. I. Feldstein, A. E. Levitin, B. A. Belov, L. I. Gromova, and T. E. Valchuk, Equivalent ionospheric currents above Antarctica during the austral summer, Antarct. Sci., 2, 267, 1990.

Papitashvili, V. O., B. A. Belov, D. S. Faermark, Y. I. Feldstein, S. A Golyshev, L. I. Gromova, and A. E. Levitin, Electric potential patterns in the northern and southern polar regions parameterized by the interplanetary magnetic field, J. Geophys. Res., 99, 13,251, 1994.

Papitashvili, V. O., C. R. Clauer, A. E. Levitin, and B. A. Belov, Relationship between the observed and modeled modulation of the dayside ionospheric convection by the IMF $B_{y}$ component, J. Geophys. Res., 100, 7715, 1995.

Papitashvili, V. O., F. J. Rich, M. A. Heinemann, and M. R. Hairston, Parameterization of the Defense Meteorological Satellite Program ionospheric electrostatic potentials by the interplanetary magnetic field strength and direction, J. Geophys. Res., 104, 177, 1999.

Papitashvili, V. O., F. Christiansen, and T. Neubert, A new model of fieldaligned currents derived from high-precision satellite magnetic field data, Geophys. Res. Lett., 29, 10.1029/2001GL014207, 2002.

Peymirat, C., and D. Fontaine, Polar cap convection patterns inferred from EISCAT observations, Ann. Geophys., 15, 403, 1997.

Reiff, P. H., and J. G. Luhmann, Solar wind control of the polar cap voltage, in Solar Wind-Magnetosphere Coupling, edited by Y. Kamide and J. A. Slavin, p. 453, Terra Sci., Tokyo, 1986.

Reiff, P. H., R. W. Spiro, and T. W. Hill, Dependence of polar cap potential drop on interplanetary parameters, J. Geophys. Res., 86, 7639, 1981

Rich, F. J., and M. Hairston, Large-scale convection patterns observed by DMSP, J. Geophys. Res., 99, 3827, 1994.

Ridley, A. J., G. Lu, C. R. Clauer, and V. O. Papitashvili, Ionospheric convection during nonsteady interplanetary magnetic field conditions, J. Geophys. Res., 102, 14,563, 1997.

Ruohoniemi, J. M., and R. A. Greenwald, Statistical patterns of high-latitude convection obtained from Goose Bay HF radar observations, $J$. Geophys. Res., 101, 21,743, 1996.

Siscoe, G., Principle results of the December 14, 1997, Meeting of the GGCM-Phase I of the GGCM Project, GEM Messenger, 8(3), 1998.

Siscoe, G. L., G. M. Erickson, B. U. Ö. Sonnerup, N. C. Maynard, K. D. Siebert, D. R. Weimer, and W. W. White, Global role of $\mathbf{E}_{\|}$in magnetopause reconnection: An explicit demonstration, J. Geophys. Res., 106, $13,015,2001$

Siscoe, G. L., G. M. Erickson, B. U. Ö. Sonnerup, N. C. Maynard, J. A. Schoendorf, K. D. Siebert, D. R. Weimer, W. W. White, and G. R. Wilson, Hill model of transpolar potential saturation: Comparisons with MHD simulations, J. Geophys. Res., 107, 10.1029/2001JA000109, 2002.

Wallis, D. D., and E. E. Budzinski, Empirical models of height-integrated conductivities, J. Geophys. Res., 86, 125, 1981.

Weimer, D. R., Models of high-latitude electric potentials derived with a least error fit of spherical harmonic coefficients, J. Geophys. Res., 100, $19,595,1995$

Weimer, D. R., A flexible, IMF dependent model of high-latitude electric potentials having "space weather" applications, Geophys. Res. Lett., 23, 2549, 1996

Weimer, D. R., An improved model of ionospheric electric potentials including substorm perturbations and application to the Geospace Environment Modeling November 24, 1996, event, J. Geophys. Res., 106, 407, 2001a.

Weimer, D. R., Maps of field-aligned currents as a function of the interplanetary magnetic field derived from Dynamic Explorer 2 data, J. Geophys. Res., 106, 12,889, 2001b.

Winglee, R. M., V. O. Papitashvili, and D. R. Weimer, Comparisons of the high-latitude ionospheric electrodynamics inferred from MHD and semiempirical models during the January 1992 GEM campaign, J. Geophys. Res., 102, 26,961, 1997.

Wolf, R. A., Effects of ionospheric conductivity on convective flow of plasma in the magnetosphere, J. Geophys. Res., 75, 4677, 1970.

V. O. Papitashvili, Space Physics Research Laboratory, University of Michigan, Ann Arbor, MI 48109-2143, USA. (papita@umich.edu)

F. J. Rich, AFRL/VSBXP, 29 Randolph Rd., Hanscom AFB, MA 017313010, USA. (frederick.rich@hanscom.af.mil) 